\title{
ENERGY-BASED APPROACH FOR FRACTURE ASSESSMENT OF SEVERAL ROCKS CONTAINING U- SHAPED NOTCHES THROUGH THE APPLICATION OF THE SED CRITERION.
}

\author{
J. Justo ${ }^{a^{*}}$, J. Castro ${ }^{\mathrm{a}}$, S. Cicero ${ }^{\mathrm{b}}$
}

${ }^{a}$ Group of Geotechnical Engineering, Universidad de Cantabria, E.T.S de Ingenieros de Caminos, Canales y Puertos, Av/ Los Castros 44, 39005, Santander, Spain

${ }^{b}$ LADICIM (Laboratory of Materials Science and Engineering), Universidad de Cantabria, E.T.S de Ingenieros de Caminos, Canales y Puertos, Av/ Los Castros 44, 39005, Santander, Spain

\footnotetext{
* Contact person: justoj@unican.es
}

\section{ABSTRACT}

This work presents an energetic continuum approach for the fracture assessment of rocks containing U-shaped notches and subjected to Mode I loading conditions. Three different methodologies are proposed in this article, all of them based on the premise that brittle failure will occur when the average strain energy density over a certain control area reaches a critical value that only depends on the material, as stated by the Strain Energy Density (SED) criterion.

The first method proposed (A) deals with the application of the SED criterion through an expression with a series of already tabulated parameters, which are particularised for the analysed rocks by rational extrapolation. Therefore, this first method avoids the use of numerical analysis. By contrast, the second method (B) aims to obtain numerically the previously extrapolated parameters, and the third method (C) directly relates the strain energy density with the applied load, without the use of those parameters.

The research is based on the results obtained from an exhaustive experimental programme comprising 300 fracture specimens tested in four-point bending conditions. These tests combine parallelepiped samples made of 6 different types of rocks (two marbles, two limestones, a sandstone and a granite) and containing 8 different notch radii (varying from $0.15 \mathrm{~mm}$ up to 15 $\mathrm{mm})$.

Thus, this work aims to show the potential, capacity and limitations of the SED criterion in rock fracture analyses, comparing with this purpose the experimentally obtained fracture loads and those predicted by the three proposed methodologies.

KEYWORDS: Strain Energy Density; Rock fracture, U-shaped notches; marble; sandstone; limestone. 


\section{INTRODUCTION}

The brittle condition of intact rocks, their high inherent strength and low toughness make them very sensitive to the presence of any defect like discontinuities, microcracks, pores, grain boundaries, etc. However, notch-type defects generate smaller stress fields and usually develop larger fracture resistance than sharp cracks. Therefore, the two types of defects should not be treated in the same way. Besides, rocks are usually subjected to relatively high loads both in nature and in industrial exploitations, which makes them even more sensitive to stress risers. All this leads to the necessity of developing accurate tools for rock fracture assessment different from the over-conservative ones derived from linear elastic fracture mechanics, where sharp crack behaviour is usually assumed for many practical situations, even for those with notch-type defects. Numerous examples can be found of traditional and conservative rock fracture mechanics, where crack-type defects are assumed for different applications of rock cutting, hydraulic fracturing or underground excavation [1-3].

Dealing with fracture analyses of notched components subjected to Mode I loading, different criteria have been proposed in the last few decades. However, establishing a general classification of these existing criteria is not easy, since the boundary between them may sometimes be diffuse. First, the Global Criterion should be mentioned, which states that fracture will occur when the notch stress intensity factor (NSIF) reaches a critical value, $K_{\rho}^{c}$, that depends on the material and notch radius [4,5]. On the other hand, [6] collects the Critical Distance methodologies, all of them using a characteristic material length parameter (the critical distance, $L$ ) when performing fracture assessment. Proceeding along similar tracks, [7] presented a criterion for brittle or quasi-brittle materials under monotonic loading, based on the cohesive zone models proposed in the past by [8] and [9] to describe stress fields and fracture processes near the defect tip. This criterion has led to successful predictions of the fracture loads of notched specimens [10-13] in parallel to other methods based on the Strain Energy Density (SED) concept [14-16]. The SED criterion combines the so-called elementary volume proposed by [17] and the local Mode I concept first proposed by [18]. It claims that brittle failure will occur when the average strain energy density over a given, well-defined, control volume is equal to a certain critical value $\left(W_{c}\right)$ dependent on the material. This energetic approach has been successfully applied to assess both the static fracture [19-22] and the fatigue behaviour $[23,24]$ of notched components (including welded structures) subjected to predominant Mode I or even Mixed Mode loading [14-16,25]. Here, blunt U-shaped notches (opening angle $2 \alpha=0$, see Fig.1) will be studied in detail.

The application of the SED criterion in materials like steels or polymers has been widely studied by many authors $[10-16,26]$. However, despite its huge potential and advantages, its 
applicability in more heterogeneous and brittle materials like rocks requires further research, since it has not been until the last few years that it has begun to be applied to rocks, as for example by $[27,28]$. For this reason, trying to fill this knowledge gap, this paper focuses on the use of the SED criterion for the fracture prediction of six different rocks containing U-shaped notches and with notch radii varying from $0.15 \mathrm{~mm}$ to $15 \mathrm{~mm}$. To this end, the study is based on the results of a systematic laboratory campaign performed by the authors of this article in $[29,30]$, which successfully applied the Theory of the Critical Distances for the fracture assessment of those six rocks.

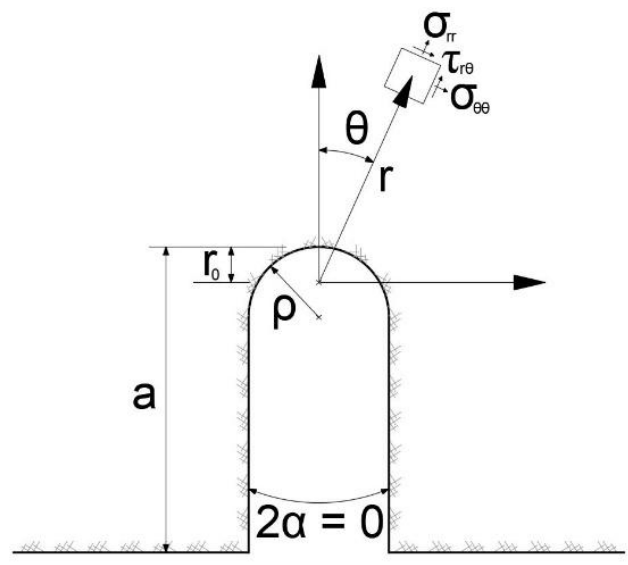

Figure 1. Coordinate system and notch geometry

with the corresponding nomenclature.

With all this, Section 2 provides an overview of the SED criterion, particularising the expressions to the geometry and conditions studied in this paper. Section 3 contains the aspects related to the experimental program, where both the analysed materials and the performed tests are described. Subsequently, three different methodologies are proposed for rock fracture load prediction, based on the analytical frame developed in Section 2. All these methodologies are individually described in Section 4, including the corresponding results and their comparison. Finally, Section 5 focuses on the general conclusions and outcomes.

\section{STRAIN ENERGY DENSITY CRITERION}

This section gathers some theoretical background on the SED criterion, which has traditionally been used to express failure conditions for materials presenting both ductile and brittle behaviour [26]. According to the SED approach, the average strain energy density $(\bar{W})$ over a certain control volume is limited by a critical value $\left(W_{c}\right)$. Thus, fracture will occur when: 
The critical strain energy $W_{c}$ only depends on the material and its value is defined by the area under the corresponding stress-strain curve (Fig. 2).

a)

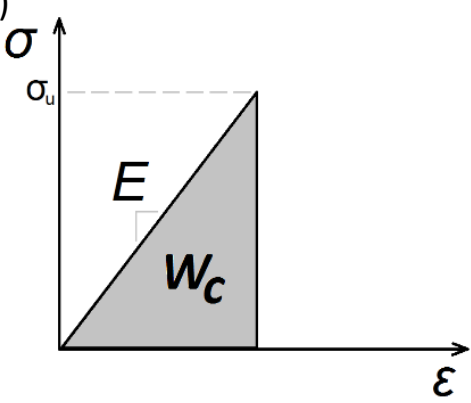

b)

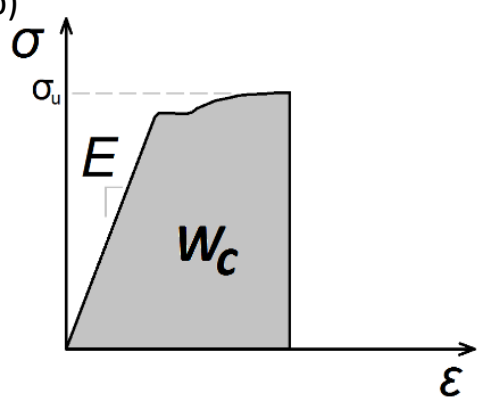

Figure 2. Stress-strain curves for an elastic and an elastoplastic material.

In the case of elastic and quasi-brittle materials like rocks (Fig. 2a), $W_{c}$ has a very simple expression and can be easily assessed through the conventional ultimate tensile strength $\left(\sigma_{u}\right)$ and the Young's modulus $(E)$ :

$$
W_{c}=\frac{\sigma_{u}^{2}}{2 E}
$$

On the other hand, the control volume over which the energy is averaged becomes an area $(\Omega)$ in plane stress or plane strain conditions. This area is defined by a radius $R_{C}$ (see Fig. 3), which depends on the ultimate tensile strength $\sigma_{u}$, the fracture toughness $K_{I C}$ and the Poisson's ratio $v$ of the material in the case of static loads. [31] provided an expression for $R_{c}$, which, in the case of $2 \alpha=0$, is as follows:

$R_{c}=\frac{(1+v)(5-8 v)}{4 \pi}\left(\frac{K_{I C}}{\sigma_{u}}\right)^{2}$

Considering the polar coordinates represented in Fig. 1 and their 3D extension to cylindrical coordinates $(r, \theta, z)$, the strain energy at a certain point for an isotropic material obeying a linear elastic law is:

$W(r, \theta, z)=\frac{1}{2 E}\left\{\sigma_{\theta \theta}^{2}+\sigma_{r r}^{2}+\sigma_{z z}^{2}+2 \tau_{r \theta}^{2}-2 v\left(\sigma_{\theta \theta} \sigma_{r r}+\sigma_{\theta \theta} \sigma_{z z}+\sigma_{r r} \sigma_{z z}-\tau_{r \theta}^{2}\right)\right\}$ 


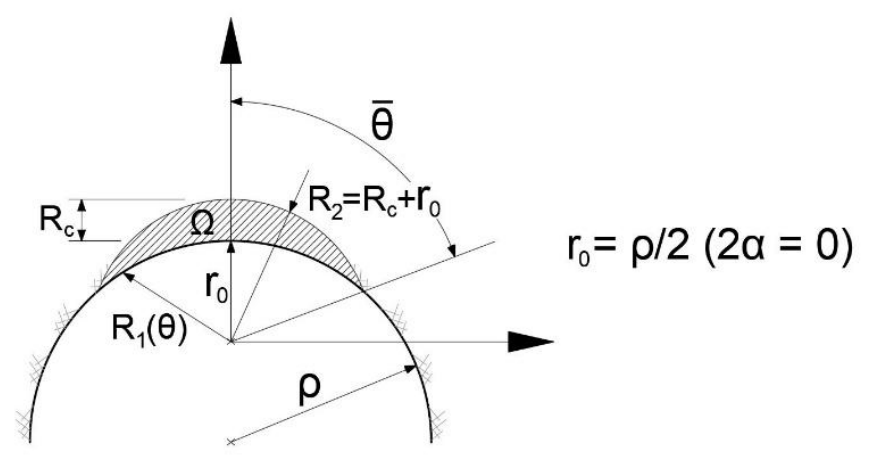

Figure 3. Control volume (area, $\Omega$ ) for U-notch under Mode I loading.

The average strain energy density over the control area $\Omega$ depicted in Fig. 3 and defined by Eq. (3) can be expressed as:

$\bar{W}=\frac{\int_{\Omega} W d \Omega}{\Omega}=\frac{1}{\Omega} \int_{-\bar{\theta}}^{\bar{\theta}} d \theta \int_{R_{1}(\theta)}^{R_{2}} W(r, \theta) r d r$

These expressions are further developed for the general case of notches with different opening angles [15,26,32]. From the mathematical development of Eq. (5), Eq. (6) is derived for the calculation of the mean value of the SED, which simplifies to a great extent the analysis of fracture processes in notched components:

$\bar{W}=0.785 \cdot H\left(v, \frac{R_{c}}{\rho}\right) \cdot \frac{\sigma_{\max }^{2}}{E}$

This expression is valid for the particular case of U-shaped notches subjected to Mode I loading conditions, where $\sigma_{\max }$ is the maximum stress at the notch tip for the applied load and $E$ is the Young's modulus of the analysed material. The function $H$, on the other hand, depends on the ratio $R_{c} / \rho$ and on the Poisson's ratio $v$ for U-shaped notches, and may be tabulated as in $[15,26]$.

Thus, rock fracture analyses can be directly made comparing the critical value of the strain energy $\left(W_{c}\right)$ defined in Eq. (2) with the mean SED value $(\bar{W})$ provided by Eq. (6). With all this, only some basic mechanical properties of the material $\left(E, v, \sigma_{u}\right.$ and $\left.K_{I C}\right)$ and the maximum principal stress at the notch tip $\left(\sigma_{\max }\right)$ are needed for fracture assessment, apart from the geometrical aspects of the notch. 


\section{EXPERIMENTAL PROGRAMME}

\subsection{MATERIALS}

The application of the SED criterion has been particularised to six representative rocks with different properties and microstructures, in an attempt to cover a wide casuistic of samples and thus prove its validity. The chosen rocks are a biotite granite (G), an oolitic limestone (0), a Moleano limestone (C), a Floresta sandstone (F), a Carrara (Italian) marble (I) and a Macael marble (M), all of them being isotropic and relatively homogeneous at the macro-scale. These rocks were previously analysed by the authors $[29,30]$, who performed the rigorous laboratory campaign that is taken as a basis in this article. Table 1 summarises some of the most relevant technical properties of each rock. More details on their microstructure and components can be consulted in $[29,30]$.

\subsection{SIMPLE COMPRESSION TESTS AND BRAZILIAN TESTS}

60 compression tests were performed in total following [33,34], six in the case of the granite and oolitic limestone and twelve for the rest of the rocks. The deformations in the two main perpendicular directions were measured using strain gauges, which allowed the Young's modulus and the Poisson's ratio to be obtained. Analogously, 60 Brazilian tests were also performed in order to obtain the tensile strength of the rocks according to [35]. Table 2 gathers the obtained average results for each material.

Table 1. Some technical properties of each material.

\begin{tabular}{lcccccc}
\hline & $(\mathbf{G})$ & $(\mathbf{O})$ & $(\mathbf{C})$ & $(\mathbf{F})$ & (I) & (M) \\
\hline Bulk density $\left(\mathrm{kg} / \mathrm{m}^{3}\right)$ & 2660 & 2540 & 2500 & 2320 & 2709 & 2715 \\
Mean grain size $(\mu \mathrm{m})$ & 1000 & 800 & 810 & 350 & 300 & 690 \\
\hline
\end{tabular}

Table 2. Main mechanical properties of each material.

\begin{tabular}{lcccccc}
\hline & $(\mathbf{G})$ & $\mathbf{( O )}$ & $\mathbf{( C )}$ & $\mathbf{( F )}$ & (I) & (M) \\
\hline Compressive strength, $\sigma_{c}(\mathrm{MPa})$ & 122.5 & 135.7 & 78.8 & 50.4 & 97.8 & 86.6 \\
Young's modulus, $E_{50}(\mathrm{GPa})$ & 45.6 & 64.1 & 38.4 & 19.6 & 57.1 & 73.4 \\
Poisson's ratio, $v$ & 0.17 & 0.33 & 0.27 & 0.24 & 0.23 & 0.28 \\
Tensile strength, $\sigma_{u}$ (MPa) & 9.00 & 7.80 & 7.08 & 3.38 & 8.69 & 8.15
\end{tabular}




\subsection{FOUR-POINT BENDING TESTS}

The geometries of the specimens tested in four-point bending conditions differ slightly from each other among the rocks studied in [29] and those analysed in [30]. In this sense, the tested specimens of both the granite (G) and the oolitic limestone $(\mathbf{O})$ consist of single edge notch beam (SENB) specimens of $150 \times 20 \times 30 \mathrm{~mm}$ (length, height, depth) with notch radii varying from 0.15 $\mathrm{mm}$ to $10 \mathrm{~mm}$ (Fig. 4a). Conversely, for the Moleano limestone (C), the Floresta sandstone (F), the Italian marble (I) and the Macael marble (M) 180×30×30 mm size SENB specimens were used with notch radii up to $15 \mathrm{~mm}$ in these cases (Fig. 4b).

All the notches, regardless of their radius, are located in the middle of the specimens with a length equal to half the height approximately, with possible slight variations attributable to the precision of the cutting processes. In any case, the relative notch length, which is defined as the ratio between the initial notch length (a) and the total height $(h)$ of the specimen, will always guarantee high constraint conditions $(0.45 \leq \mathrm{a} / \mathrm{h} \leq 0.55)$.
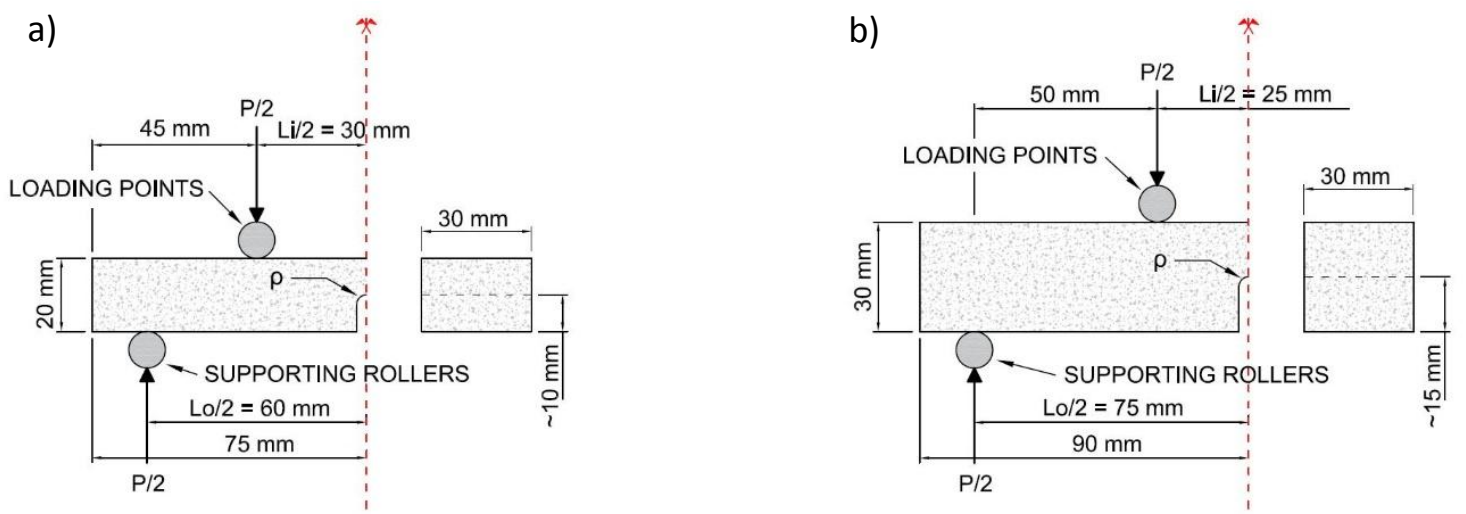

Figure 4. Schemes of the tested SENB specimens. Notch radii $(\rho)$ vary from $0.15 \mathrm{~mm}$ up to $10 \mathrm{~mm}$ (a) or up to $15 \mathrm{~mm}$ (b).

The indications on these geometrical aspects and the experimental procedure followed are specified in $[36,37]$. This methodology allows the fracture toughness $\left(K_{I C}\right)$ of the tested rocks to be obtained and it was first proposed by [38] for SENB ceramic specimens tested in four-point bending conditions. The four-point bending tests ensure pure and constant bending conditions between the inner loading points, and the described geometries enable plane strain conditions to be considered.

As mentioned above, 300 four-point bending test have been performed: at least six for each material and notch radius, and twelve in some of the cases for verification. Table 3 presents the experimental results for each material. First, the fracture toughness $\left(K_{I C}\right)$ is displayed for the six rocks. Both [29] and [30] describe in detail, following [36,37], how this parameter is obtained. 
Finally, the average failure loads as well as their standard deviations are also indicated for each material and notch radius.

Table 3. Fracture toughness, average failure loads and standard deviation of the failure loads.

\begin{tabular}{cccccccc}
\hline & & (G) & (O) & (C) & (F) & (I) & (M) \\
\hline Fracture toughness, $K_{I C}$ (MPa.m ${ }^{1 / 2}$ ) & 1.24 & 0.72 & 0.73 & 0.37 & 0.74 & 1.14 \\
\hline$P_{\text {EXP. }}(\mathrm{N})$ for $\rho=0.15 \mathrm{~mm}$ & Mean: & 696.71 & 358.66 & 375.05 & 175.17 & 353.45 & 552.12 \\
& S. Dev.: & 100.38 & 31.32 & 62.42 & 55.74 & 65.19 & 79.45 \\
\hline \multirow{2}{*}{$P_{\text {EXP. }}(\mathrm{N})$ for $\rho=0.5 \mathrm{~mm}$} & Mean: & 578.61 & 352.76 & 346.68 & 177.07 & 344.75 & 576.67 \\
& S. Dev.: & 44.35 & 24.18 & 43.57 & 18.33 & 70.52 & 53.28 \\
\hline$P_{\text {EXP. }}(\mathrm{N})$ for $\rho=1 \mathrm{~mm}$ & Mean: & 546.81 & 362.14 & 411.10 & 152.49 & 333.81 & 521.62 \\
& S. Dev.: & 47.65 & 15.68 & 50.12 & 20.98 & 57.04 & 58.43 \\
\hline$P_{\text {EXP. }}(\mathrm{N})$ for $\rho=2 \mathrm{~mm}$ & Mean: & 586.03 & 357.62 & 385.20 & 183.01 & 340.12 & 506.98 \\
& S. Dev.: & 61.57 & 7.38 & 35.21 & 23.47 & 35.56 & 122.24 \\
\hline$P_{\text {EXP. }}(\mathrm{N})$ for $\rho=4 \mathrm{~mm}$ & Mean: & 571.95 & 378.92 & 413.79 & 186.15 & 312.67 & 571.73 \\
& S. Dev.: & 63.37 & 64.22 & 83.73 & 23.26 & 42.14 & 140.29 \\
\hline$P_{\text {EXP. }}(\mathrm{N})$ for $\rho=7 \mathrm{~mm}$ & Mean: & 642.32 & 422.99 & 494.01 & 229.15 & 354.81 & 748.71 \\
& S. Dev.: & 26.08 & 18.30 & 45.91 & 14.89 & 60.43 & 115.33 \\
\hline$P_{\text {EXP. }}(\mathrm{N})$ for $\rho=10 \mathrm{~mm}$ & Mean: & 558.70 & 432.66 & 477.34 & 208.95 & 368.05 & 751.12 \\
& S. Dev.: & 71.36 & 23.71 & 84.74 & 13.69 & 63.83 & 54.33 \\
\hline$P_{\text {EXP. }}(\mathrm{N})$ for $\rho=15 \mathrm{~mm}$ & Mean: & - & - & 430.37 & 205.76 & 371.55 & 672.64 \\
& S. Dev.: & - & - & 59.71 & 13.64 & 48.89 & 178.94 \\
\hline
\end{tabular}

\section{STUDY METHODOLOGIES AND RESULTS}

Three different methodologies are proposed in this section for rock fracture load prediction. They are all based on the failure criterion defined by Eq. (1), which states that failure occurs when the mean strain energy density $(\bar{W})$ over the control area $(\Omega)$ reaches a critical value $\left(W_{c}\right)$, that is, when Eq. (7) is fulfilled:

$W_{c}=\bar{W}=0.785 \cdot H\left(v, \frac{R_{c}}{\rho}\right) \cdot \frac{\sigma_{\max }^{2}}{E}$

Table 4 collects the values of $W_{c}$ for each of the six rocks, which correspond to the areas under the stress-strain curves depicted in Fig. 2 and calculated by Eq. (2).

On the other hand, the control area $\Omega$ is defined by the radius $R_{c}$ as shown in Fig. 3. These radii are calculated for each material using Eq. (3) and the corresponding results are gathered in Table 5. The obtained $R_{C}$ values are of the order of millimetres due to the relatively low values of the tensile strength $\left(\sigma_{u}\right)$ of rocks, which appears dividing in Eq. (3). As a consequence, the size 
of $\Omega$ will be relatively large in the case of rocks. With all this, an individual and detailed description is given below for each of the proposed methodologies, focusing on the particularities as well as on the associated advantages and limitations. Likewise, all the results are described and discussed in the following subsections, comparing the different outcomes corresponding to each of the methods.

Table 4. Critical SED values $\left(W_{c}\right)$ of each material.

\begin{tabular}{ccccccc}
\hline & $(\mathbf{G})$ & $(\mathbf{O})$ & (C) & (F) & (I) & (M) \\
\hline$W_{c}(K P a)$ & 0.8882 & 0.4746 & 0.6527 & 0.2914 & 0.6613 & 0.4525 \\
\hline
\end{tabular}

Table 5. Values of $R_{c}$ of each material.

\begin{tabular}{ccccccc}
\hline & $(\mathbf{G})$ & $\mathbf{( O )}$ & $\mathbf{( C )}$ & $\mathbf{( F )}$ & (I) & (M) \\
\hline$R_{c}(\mathrm{~mm})$ & 6.4333 & 2.1283 & 3.0513 & 3.6419 & 2.2429 & 5.5005 \\
\hline
\end{tabular}

\subsection{METHOD A: PUBLISHED VALUES OF $\boldsymbol{H}$}

This first technique constitutes the simplest and most straightforward methodology, as the use of numerical modelling is avoided. Method A deals with analytical solutions based on the direct application of Eq. (7) through already tabulated values of the $H$ function, as those proposed by $[15,26]$ and shown in Table 6 .

Table 6. Values of the $H$ function for U-notched specimens [26].

\begin{tabular}{lccccccc}
\hline \multicolumn{1}{c}{$R_{c} / \rho$} & $v=0.10$ & $v=0.15$ & $v=0.20$ & $v=0.25$ & $v=0.30$ & $v=0.35$ & $v=0.40$ \\
\hline $\mathbf{0 . 0 0 0 5}$ & 0.6294 & 0.6215 & 0.6104 & 0.5960 & 0.5785 & - & - \\
$\mathbf{0 . 0 0 1}$ & 0.6286 & 0.6207 & 0.6095 & 0.5952 & 0.5777 & - & - \\
$\mathbf{0 . 0 0 5}$ & 0.6225 & 0.6145 & 0.6033 & 0.5889 & 0.5714 & - & - \\
$\mathbf{0 . 0 1}$ & 0.6149 & 0.6068 & 0.5956 & 0.5813 & 0.5638 & 0.5432 & 0.5194 \\
$\mathbf{0 . 0 5}$ & 0.5599 & 0.5515 & 0.5401 & 0.5258 & 0.5086 & 0.4884 & 0.4652 \\
$\mathbf{0 . 1}$ & 0.5028 & 0.4942 & 0.4828 & 0.4687 & 0.4518 & 0.4322 & 0.4099 \\
$\mathbf{0 . 3}$ & 0.3528 & 0.3445 & 0.3341 & 0.3216 & 0.3069 & 0.2902 & 0.2713 \\
$\mathbf{0 . 5}$ & 0.2672 & 0.2599 & 0.2508 & 0.2401 & 0.2276 & 0.2135 & 0.1976 \\
$\mathbf{1}$ & 0.1590 & 0.1537 & 0.1473 & 0.1399 & 0.1314 & 0.1217 & 0.1110 \\
\hline
\end{tabular}


The range of values of $R_{c} / \rho$ of Table 6 vary from 0.0005 up to 1 , which may be sufficient for materials such as steels or polymers $[10-16,26]$, but falls short for rocks where that ratio reaches much higher values, of around 43 in the case of the studied granite for instance. For this reason, this first method proposes an extrapolation of the tabulated values of $H$, considering the corresponding Poisson's ratio $v$ for each rock. Fig. 5 shows the case of the Moleano limestone (C) as an example, representing the values of $H$ that correspond to $v=0.27$ (from linear interpolation of the values in Table 6) against the ratio $R_{c} / \rho$.

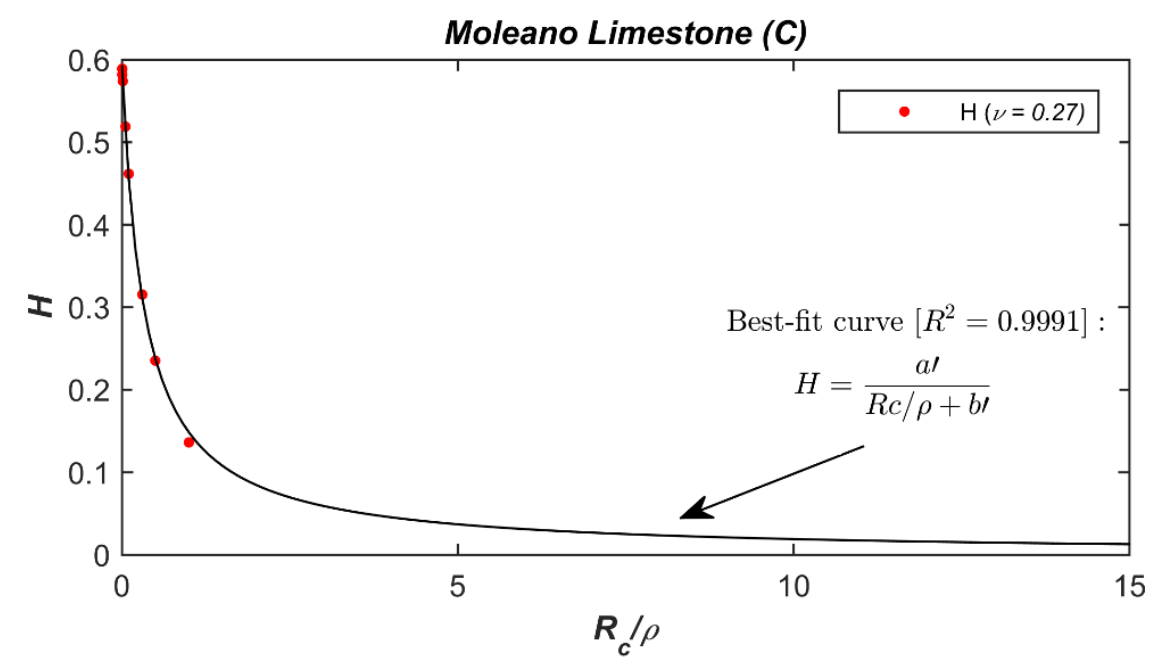

Figure 5. Extrapolation of the $H$ function for $v=0.27$ (e.g. Moleano Limestone (C)).

In order to find the equation that best fits the tabulated values (dots in Fig. 5) some considerations must be taken into account first. In the case of a crack $(\rho=0)$, both the ratio $R_{c} / \rho$ and the maximum stress at the tip tend to infinite $\left(\sigma_{\max }=\infty\right)$. Therefore, $H$ must be zero to fulfil Eq. (7); by contrast, in the case of an infinite notch radius $(\rho=\infty)$, the studied piece will develop a certain resistance and the maximum stress will have a finite value. Consequently, $H$ will also have a finite value to accomplish Eq. (7). With all this, the equation sought will have a horizontal asymptote for $\mathrm{H}=0$ and will cut the vertical axis $\left(R_{c} / \rho=0\right)$ in a certain finite value, as shown in Fig. 5. Among all the equations that meet these conditions, a rational equation of order 1 has the simplest form, provides a good adjustment and requires the fewest parameters:

$H=\frac{a^{\prime}}{R_{c} / \rho+b^{\prime}}$

where $a^{\prime}$ and $b^{\prime}$ are the only two parameters needed for the correct adjustment of the curve. Table 7 collects the corresponding values of the parameters for the best-fit curves of each 
material. Proceeding in the same way, Table 6 can be extended for larger values of $R_{c} / \rho$ as those shown in Table 8.

Table 7. Fitting parameters for the first order rational curves described by Eq. (8).

\begin{tabular}{ccccccc}
\hline & $(\mathbf{G})$ & $(\mathbf{O})$ & $(\mathbf{C})$ & $\mathbf{( F )}$ & (I) & (M) \\
& $v=0.17$ & $v=0.33$ & $v=0.27$ & $v=0.24$ & $v=0.23$ & $v=0.28$ \\
\hline$a^{\prime}$ & 0.2199 & 0.1811 & 0.1973 & 0.2047 & 0.2070 & 0.1947 \\
$b^{\prime}$ & 0.3546 & 0.3181 & 0.3331 & 0.3400 & 0.3422 & 0.3306 \\
\hline
\end{tabular}

Table 8. Extrapolated values of the $H$ function.

\begin{tabular}{lccccccc}
\hline \multicolumn{1}{c}{$R_{c} / \rho$} & $v=0.10$ & $v=0.15$ & $v=0.20$ & $v=0.25$ & $v=0.30$ & $v=0.35$ & $v=0.40$ \\
\hline $\mathbf{2}$ & 0.0982 & 0.0950 & 0.0911 & 0.0866 & 0.0815 & 0.0750 & 0.0688 \\
$\mathbf{5}$ & 0.0433 & 0.0418 & 0.0400 & 0.0379 & 0.0356 & 0.0326 & 0.0298 \\
$\mathbf{1 0}$ & 0.0224 & 0.0216 & 0.0207 & 0.0196 & 0.0184 & 0.0168 & 0.0153 \\
$\mathbf{2 0}$ & 0.0114 & 0.0110 & 0.0105 & 0.0100 & 0.0093 & 0.0085 & 0.0078 \\
$\mathbf{5 0}$ & 0.0046 & 0.0044 & 0.0042 & 0.0040 & 0.0038 & 0.0034 & 0.0031 \\
\hline
\end{tabular}

Once the $H$ function is known from the extrapolation of the tabulated values, the maximum stress at the notch tip $\left(\sigma_{\max }\right)$ corresponding to the failure situation becomes the only unknown and, therefore, can be calculated using Eq. (7). The resultant value should be consistent with the expression proposed by Creager and Paris [39], which defines, for long and narrow notches, the stress distribution as a function of distance from the notch tip $(r)$, the stress intensity factor $\left(K_{I}\right.$, as defined for crack-like defects), and the proper notch radius $(\rho)$ :

$\sigma(r)=\frac{K_{I}}{\sqrt{\pi}} \cdot \frac{2(r+\rho)}{(2 r+\rho)^{3 / 2}}$

The stress will be maximum at the notch tip for $r=0$. Thus, Eq. (9) becomes:

$\sigma(0)=\sigma_{\max }=\frac{K_{I}}{\sqrt{\pi}} \cdot \frac{2 \rho}{\rho^{3 / 2}}$

$K_{I}$ can therefore be derived from Eq. (10), considering the value of $\sigma_{\max }$ obtained from Eq. (7). Likewise, there is an extensive bibliography that collects analytical solutions of $K_{I}$ for common test specimens (e.g., [40]), for which: 
$K_{I}=\frac{P}{B \sqrt{h}} Y$

where $B$ is the thickness and $h$ is the height of the samples, and $Y$ is a geometrical factor that depends on the relative notch length $(a / h)$ and the specimen geometry. For the test specimens analysed here $[36,38]$ :

$Y=\frac{3 \cdot\left(L_{o}-L_{i}\right) \cdot\left(\frac{\mathrm{a}}{h}\right)^{1 / 2} \cdot X}{2 h \cdot\left(1-\frac{\mathrm{a}}{h}\right)^{3 / 2}}$

with

$X=1.9887-\left[\frac{\left(3.49-0.68 \frac{\mathrm{a}}{h}-1.35\left(\frac{\mathrm{a}}{h}\right)^{2}\right) \cdot \frac{\mathrm{a}}{h} \cdot\left(1-\frac{\mathrm{a}}{h}\right)}{\left(1+\frac{\mathrm{a}}{h}\right)^{2}}\right]-1.32 \cdot \frac{\mathrm{a}}{h}$

where $L_{o}$ and $L_{i}$ are the spans between the outer supporting rollers and the inner loading points as depicted in Fig. 4.

Eventually, the loads $P$ obtained by inverting Eq. (11) correspond to the fracture loads predicted by the SED criterion. Based on these outcomes, Fig. 6 gathers the results for the six analysed materials, representing the ratio of the predicted failure load $\left(P_{S E D}\right)$ and the experimental failure load $\left(P_{\text {EXP. }}\right)$, against the notch radius $(\rho)$. The dots correspond to the individual results for each of the tested specimens, while the solid line represents the mean prediction for the different notch radii. Additionally, three horizontal lines have been included in the graphs. The horizontal solid line stands for the theoretically exact prediction, where $P_{S E D} / P_{\text {EXP. }}=1$. The values below this line imply an underestimation of the fracture load, while the values above it imply an overestimation. On the other hand, the dashed lines constitute the envelope of $\pm 20 \%$, which tries to encompass the intrinsic uncertainties of the performed laboratory tests and, especially, the variability of the fracture results due to the heterogeneous nature of the materials. Even though the variability of the experimental results is greater than $20 \%$ in some of the cases, this strip delimited by the dashed lines will be considered as representative of the accuracy of the predictions for mean values. 

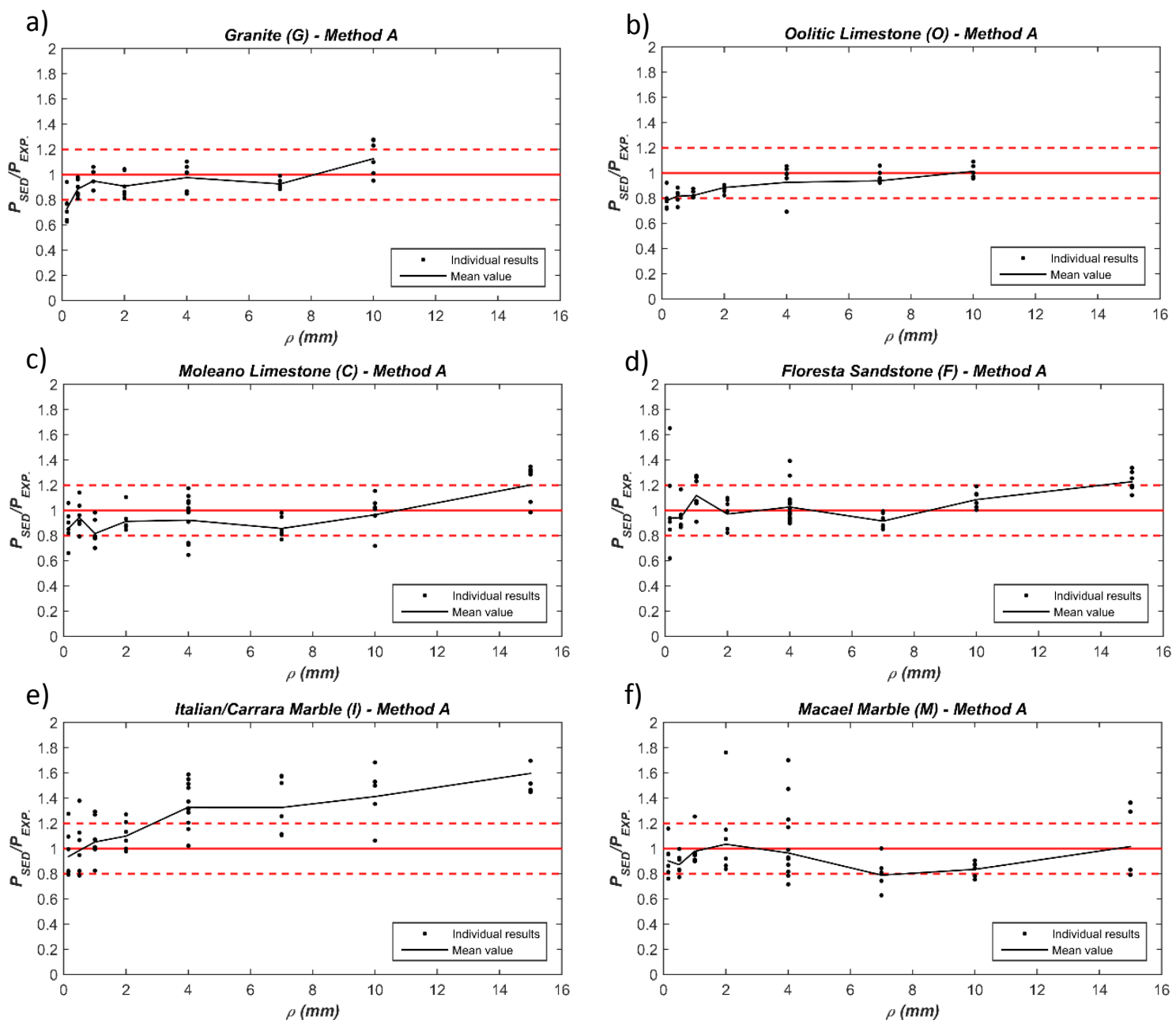

Figure 6. SED predictions (Method A) of the failure load for each rock.

In accordance with Fig. 6, Method A offers reasonable results even for the largest notches beyond the application range of Eq. (9). Nevertheless, the Carrara Marble (Fig. 6e) shows the worst predictions with almost $50 \%$ of the individual results outside the established limits, probably because of the significant variability of its experimental results, which make it difficult to obtain representative values of its key mechanical parameters, such as the fracture toughness or the tensile strength. The results for the rest of the rocks fall acceptably within the upper and lower bands, with more than $70 \%$ of the dots inside these limits in the case of the Macael Marble (Fig. 6f) and more than $80 \%$ for the remaining rocks (Fig. 6a, 6b, 6c and 6d). Finally, the predictions tend to be more conservative for the smaller notch radii.

\subsection{METHOD B: NUMERICAL EVALUATION OF FUNCTION $\boldsymbol{H}$}

The second proposed method deals with numerical modelling in order to generate a new table for the $H$ function, adapted to the range of $R_{c} / \rho$ values appropriate for the analysed rocks. 
The $H$ function is theoretically independent of the notch radius $\left(\rho_{\text {fem }}\right)$ considered in the calculation model, only depending on $v$ and on the ratio $R_{c} / \rho$ as long as U-shaped notches $(2 \alpha=0)$ are considered. For this reason, from a strict point of view, it is necessary to conduct a single numerical model for each material with a specific notch radius, thereby obtaining the values of $H$ that correspond to each $R_{c} / \rho$ with this unique model. Theoretically, for a given value of that ratio and for each $v$, only one value of $H$ is possible. Consequently, any combination of $R_{c}$ and $\rho$ offering the same ratio will also provide the same $H$ for a certain material. However, this statement is rather limited, since the bigger the notch radius $(\rho)$ the larger the control area (defined by $R_{c}$ ) for a given value of $R_{c} / \rho$, and the other way around. Fig. 7 shows, as an example, the case of the Moleano Limestone. It is observed how, for a certain value of $R_{c} / \rho$, the size of the control area increases with the size of the modelled notch, representing the cases of $\rho_{\text {fem }}$ $=1, \rho_{\text {fem }}=2$ and $\rho_{\text {fem }}=4 \mathrm{~mm}$, respectively. Thus, the chosen notch radius for the numerical model will influence the dimensions of the control area $(\Omega)$ over which the strain energy is averaged. The lower bound of this area is delimited by the refinement of the mesh, while the upper bound has a double limitation. First, the geometry of the numerical model physically limits the maximum size of that area and, second, the closed form expressions are only valid in the vicinity of the notch. In fact, the applied methodology assumes that the local stress field assessed from the notch tip to a distance $R_{c}$ is governed by the Generalised Notch Stress Intensity Factor $K_{I}$, which is true up to a distance where the influence of the outer limit of the specimen is negligible, but is no longer valid for large values of $R_{c}$ where the influence of the boundary becomes noticeable.
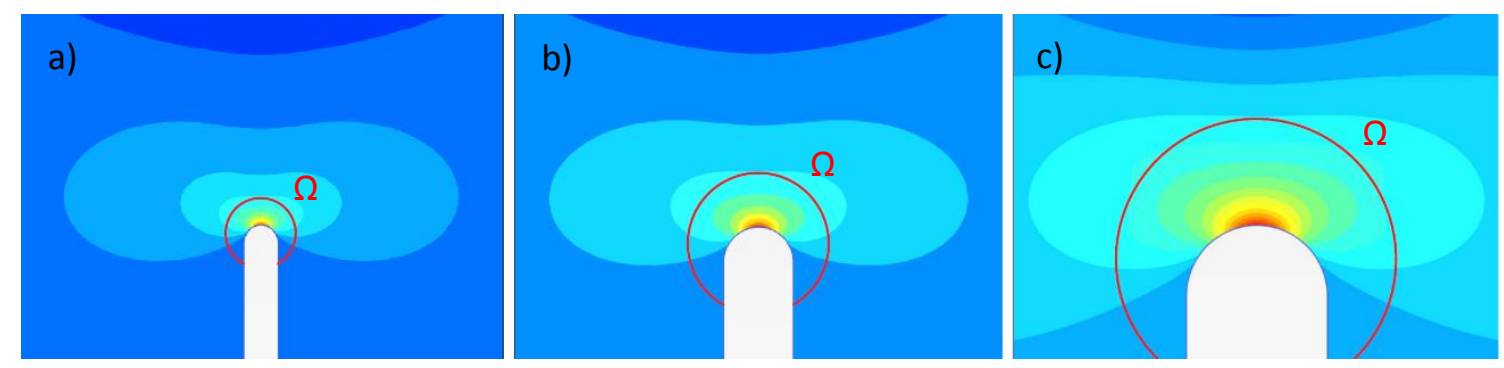

Figure 7. Control areas $(\Omega)$ of the Moleano Limestone (C) for $R_{c} / \rho=1.526$ (corresponding to $R_{c}=3.0513 \mathrm{~mm}$ and $\rho=2 \mathrm{~mm}$ ) and for a model with (a) $\rho_{\text {fem }}=1$, (b) 2 and (c) $4 \mathrm{~mm}$.

In order to use a single numerical model for each of the rocks with a single notch radius $\left(\rho_{\text {fem }}\right)$, the considered critical radius $R_{c_{-} \text {fem }}$ in the calculation will vary so as to maintain the ratio $R_{c} / \rho$. Thus, $R_{C_{-} f e m}$ will have to fulfil the following expression: 
$\frac{R_{c}}{\rho}=\frac{R_{c_{-} f e m}}{\rho_{\text {fem }}} \rightarrow R_{c_{-} f e m}=R_{C} \cdot \frac{\rho_{\text {fem }}}{\rho}$

According to Eq. (14), when the notch radius that is implemented in the model $\left(\rho_{\text {fem }}\right)$ is larger than the notch radius that is being assessed in the fracture prediction $(\rho)$, the value of $R_{C_{-} f e m}$ that is considered in the calculation will be larger than the critical $R_{C}$ corresponding to the rock. Therefore, it can be concluded that the $\operatorname{larger} \rho_{\text {fem }}$ is selected for the model, the larger the required control areas. By contrast, the control area will get smaller as lower values of $\rho_{\text {fem }}$ are considered in the model. Therefore, it is necessary to define a notch radius for the numerical model that ensures an adequate control area $(\Omega)$ size to obtain the optimum results.

A sensitivity analysis has been carried out in order to determine the most suitable notch radius to be implemented in the model. First of all, a notch with $\rho_{\text {fem }}=1 \mathrm{~mm}$ has been considered, obtaining the corresponding values of $H$. These values have proven to be very similar to those proposed by [26] and shown in Table 6, which were, in origin, obtained numerically for $\rho_{f e m}=1 \mathrm{~mm}$. Thus, the defined model has been validated and can be considered suitable for the numerical analysis. Likewise, the numerical models made with the rest of the available notch sizes have also been checked, and it was observed that the best results correspond to the model with the smallest notch radius, $\rho_{f e m}=0.15 \mathrm{~mm}$, while the largest radii offer the poorest results. This generality makes sense, since the control area $(\Omega)$ becomes larger as higher values of $\rho_{\text {fem }}$ are implemented in the model, even exceeding its geometric limits. For these reasons and for the sake of simplicity, only the results for $\rho_{\text {fem }}=0.15 \mathrm{~mm}$ and $\rho_{\text {fem }}=1 \mathrm{~mm}$ are presented here.

In this work, a finite element code called PLAXIS 2D [41] has been used to model the test specimens. A linear elastic model is used to simulate the rocks, so only two parameters are needed: the Young's modulus $(E)$ and the Poisson's ratio $(v)$. The applied load is not determinant, since $H$ is independent of the maximum stress at the notch tip $\left(\sigma_{\max }\right)$ and proportional to the mean strain energy density $(\bar{W})$, which are the only required outputs for this second proposed method. Both Table 9 and Table 10 gather, on one side, the $R_{c}$ and $v$ values of the analysed rocks and, on the other, the $H$ values for the different notch radii. These values are directly obtained by inverting Eq. (6), both from the model with $\rho_{\text {fem }}=1 \mathrm{~mm}$ and $\rho_{\text {fem }}=$ $0.15 \mathrm{~mm}$, respectively. All the values in Table 6 and Table 9 are obtained numerically with a notch radius $\rho_{\text {fem }}=1 \mathrm{~mm}$, but only those indicated in bold are comparable with the values proposed by [26] in Table 6 , since the corresponding $R_{c} / \rho$ ratios are in the same range. By 
contrast, the remaining values are outside that range and must therefore be compared with the extrapolated values of the first methodology.

Table 9. $\mathrm{H}$ function obtained numerically from the model with $\rho_{f e m}=1 \mathrm{~mm}$ (Method B).

\begin{tabular}{lcccccc}
\hline & $(\mathbf{G})$ & $(\mathbf{O})$ & $\mathbf{( C )}$ & $\mathbf{( F )}$ & $\mathbf{( I )}$ & $\mathbf{( M )}$ \\
\hline$v$ & 0.17 & 0.33 & 0.27 & 0.24 & 0.23 & 0.28 \\
$R_{c}(\mathrm{~mm})$ & 6.4333 & 2.1283 & 3.0513 & 3.6419 & 2.2429 & 5.5005 \\
\hline$\rho=0.15 \mathrm{~mm}$ & 0.0032 & 0.0049 & 0.0037 & 0.0032 & 0.0051 & 0.0027 \\
$\rho=0.5 \mathrm{~mm}$ & 0.0058 & 0.0191 & 0.0155 & 0.0130 & 0.0236 & 0.0072 \\
$\rho=1 \mathrm{~mm}$ & 0.0135 & 0.0420 & 0.0344 & 0.0295 & 0.0509 & 0.0174 \\
$\rho=2 \mathrm{~mm}$ & 0.0328 & 0.0907 & 0.0726 & 0.0629 & 0.1066 & 0.0379 \\
$\rho=4 \mathrm{~mm}$ & 0.0719 & $\mathbf{0 . 1 9 1 0}$ & $\mathbf{0 . 1 5 2 4}$ & $\mathbf{0 . 1 3 1 1}$ & $\mathbf{0 . 2 1 8 6}$ & 0.0797 \\
$\rho=7 \mathrm{~mm}$ & $\mathbf{0 . 1 3 1 8}$ & $\mathbf{0 . 2 9 3 9}$ & $\mathbf{0 . 2 5 7 0}$ & $\mathbf{0 . 2 2 8 1}$ & $\mathbf{0 . 3 2 9 0}$ & $\mathbf{0 . 1 4 5 6}$ \\
$\rho=10 \mathrm{~mm}$ & $\mathbf{0 . 1 9 0 9}$ & $\mathbf{0 . 3 5 6 4}$ & $\mathbf{0 . 3 2 6 4}$ & $\mathbf{0 . 3 0 1 8}$ & $\mathbf{0 . 3 9 2 9}$ & $\mathbf{0 . 2 0 9 1}$ \\
$\rho=15 \mathrm{~mm}$ & - & - & $\mathbf{0 . 3 9 5 5}$ & $\mathbf{0 . 3 7 6 2}$ & $\mathbf{0 . 4 5 9 3}$ & $\mathbf{0 . 2 8 8 9}$ \\
\hline
\end{tabular}

Table 10. $H$ function obtained numerically from the model with $\rho_{\text {fem }}=0.15 \mathrm{~mm}$ (Method B).

\begin{tabular}{lcccccc}
\hline & $(\mathbf{G})$ & $(\mathbf{O})$ & $\mathbf{( C )}$ & $\mathbf{( F )}$ & $\mathbf{( I )}$ & $\mathbf{( M )}$ \\
\hline$v$ & 0.17 & 0.33 & 0.27 & 0.24 & 0.23 & 0.28 \\
$R_{c}(\mathrm{~mm})$ & 6.4333 & 2.1283 & 3.0513 & 3.6419 & 2.2429 & 5.5005 \\
\hline$\rho=0.15 \mathrm{~mm}$ & 0.0025 & 0.0077 & 0.0069 & 0.0059 & 0.0102 & 0.0035 \\
$\rho=0.5 \mathrm{~mm}$ & 0.0110 & 0.0270 & 0.0243 & 0.0214 & 0.0354 & 0.0131 \\
$\rho=1 \mathrm{~mm}$ & 0.0231 & 0.0542 & 0.0482 & 0.0428 & 0.0699 & 0.0266 \\
$\rho=2 \mathrm{~mm}$ & 0.0472 & 0.1101 & 0.0948 & 0.0848 & 0.1348 & 0.0529 \\
$\rho=4 \mathrm{~mm}$ & 0.0937 & 0.2373 & 0.1939 & 0.1663 & 0.2940 & 0.1022 \\
$\rho=7 \mathrm{~mm}$ & 0.1614 & 0.3375 & 0.3340 & 0.3121 & 0.4539 & 0.1796 \\
$\rho=10 \mathrm{~mm}$ & 0.2269 & 0.4242 & 0.4391 & 0.4087 & 0.5148 & 0.2886 \\
$\rho=15 \mathrm{~mm}$ & - & - & 0.5001 & 0.5113 & 0.5495 & 0.3937 \\
\hline
\end{tabular}

Once the $H$ function is known, the predicted failure load $\left(P_{S E D}\right)$ is calculated proceeding in the same way as in Method A, starting from Eq. (7). The pertinent results are shown in Fig. 8 and Fig. 9. 
a)

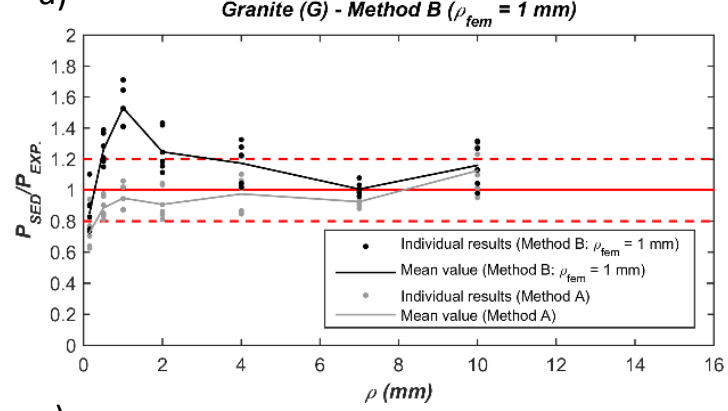

C) Moleano Limestone $(C)-$ Method B $\left(\rho_{\text {fem }}=1 \mathrm{~mm}\right)$

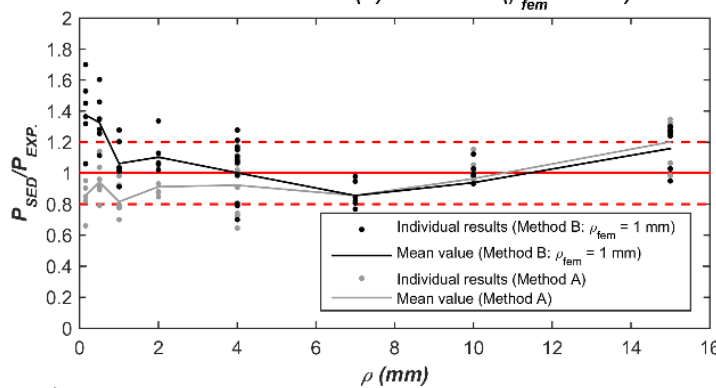

e)

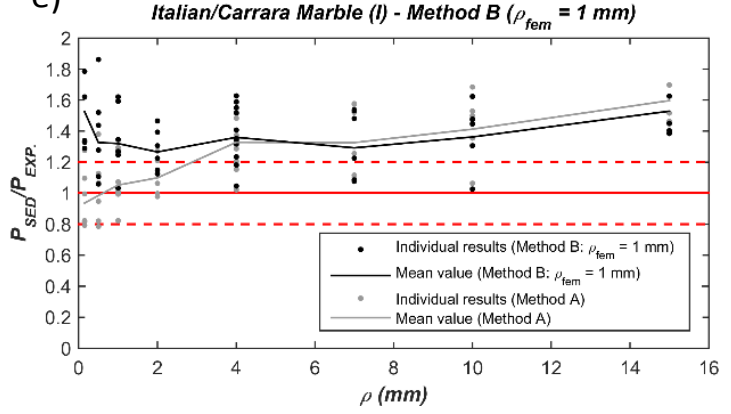

b)

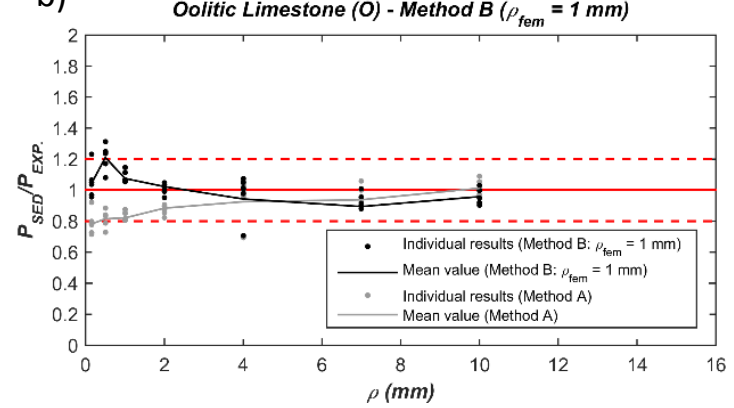

d) Floresta Sandstone $(F)-\operatorname{Method} B\left(\rho_{\text {fem }}=1 \mathrm{~mm}\right)$

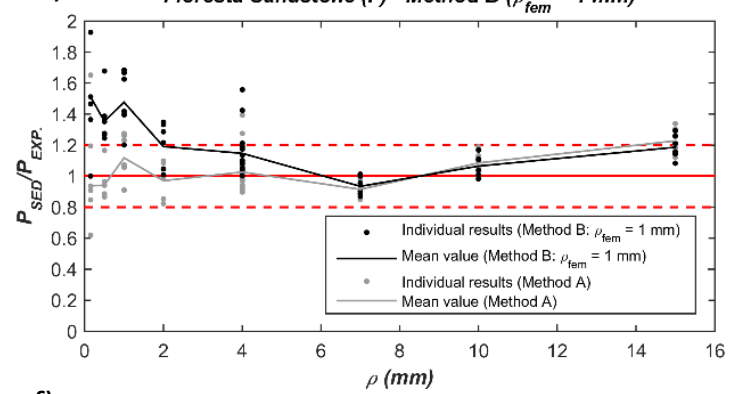

f)

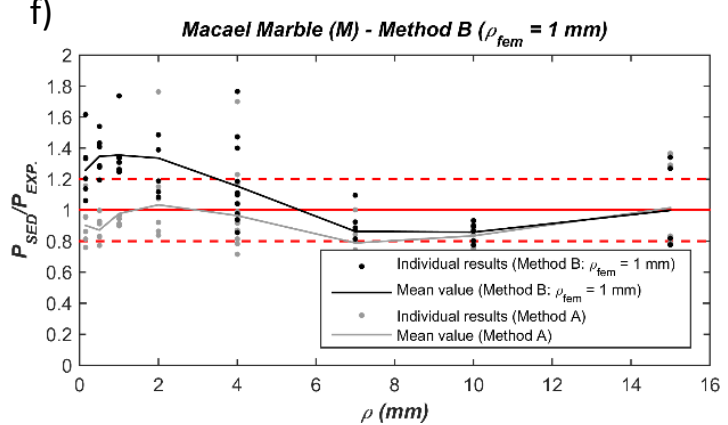

Figure 8. SED predictions (Method B: $\rho_{\text {fem }}=1 \mathrm{~mm}$ ) of the failure load for each rock.

Fig. 8 shows the results obtained using the $H$ values from the numerical model with $\rho_{\text {fem }}=$ $1 \mathrm{~mm}$ superposed on the previous results depicted in Fig. 7. For the range of comparable $R_{c} / \rho$ values, that is, the non-extrapolated part but the overlapping one, the coincidence should be reflected in the last segment of the plotted curves, from $\rho=4 \mathrm{~mm}$ onwards for the oolitic limestone (Fig. 8b), Moleano limestone (Fig. 8c), Floresta sandstone (Fig. 8d) and Carrara marble (Fig. 8e) and from $\rho=7 \mathrm{~mm}$ on for the granite (Fig. 8a) and Macael marble (Fig. 8f). All the curves reveal a clear similarity in this range of values, except the granite that shows some differences. On the contrary, the initial part of the curves is to be compared with the extrapolated values of Method A. It can be observed that the adjustment between both curves is somewhat worse in this zone. A generalized overestimation is observed in Fig. 8 for the smallest notch radii in all the analysed rocks. The control area over which the strain energy density is averaged exceeds the boundary condition in these cases, which explains the observed overestimations. However, the predictions for the biggest notches (corresponding to the relatively small control areas) offer more accurate predictions according to Fig. 8 . Thus, it can be concluded that the numerical 
model with $\rho_{f e m}=1 \mathrm{~mm}$ might be sufficient to obtain the $H$ for $R_{c} / \rho$ ratios common in materials like steels or polymers with lower critical radii $\left(R_{c}\right)$, but falls short in materials like rocks where $R_{C}$ is of the order of several millimeters, specially in the case of evaluating the fracture of small notches.
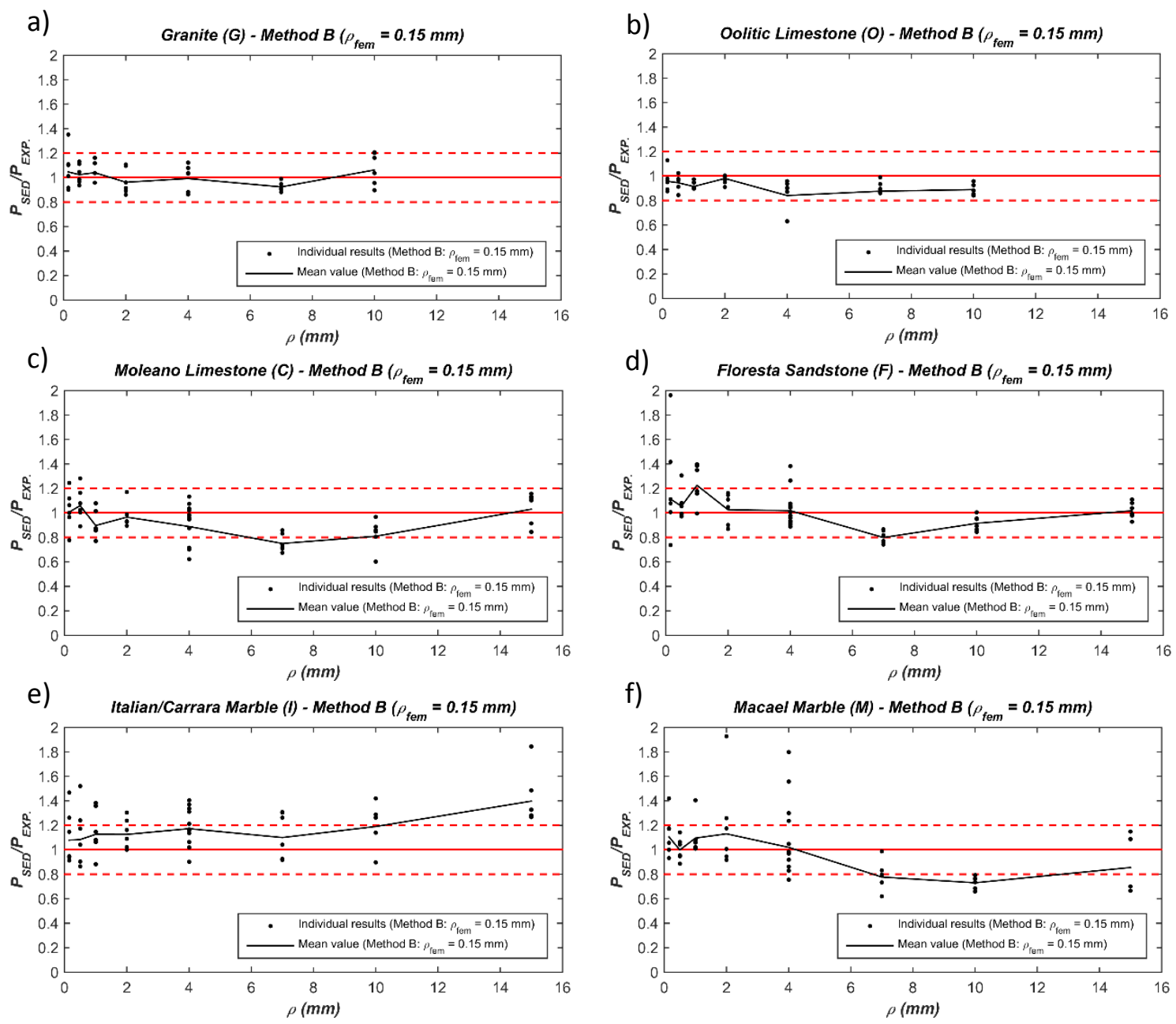

Figure 9. SED predictions (Method B: $\rho_{\text {fem }}=0.15 \mathrm{~mm}$ ) of the failure load for each rock.

Finally, the results obtained using $H$ values from the numerical model with $\rho_{f e m}=0.15 \mathrm{~mm}$ are shown in Fig. 9. The accuracy of the predicted failure loads $\left(P_{S E D}\right)$ is reasonable in all the studied rocks, even for the Carrara Marble which offered the worst results in the previous cases. More than $80 \%$ of the individual results fall, on average, within the $\pm 20 \%$ strip defined by the dashed lines, except the Carrara Marble, where the percentage is considerably lower despite the improvement in the mean results (Fig. 9e). Moreover, the tendency observed when applying the extrapolation (Method A), consisting in obtaining less conservative results when increasing the notch radius, is not perceived here (neither in Fig. 8, nor in Fig.9). 


\subsection{METHOD C: NUMERICAL EVALUATION OF $\bar{W}$}

The two previous methods are based on [39] to define the stress distribution at the notch tip (Eq. (9)). This corresponding expression is theoretically valid only for long and narrow notches, so the largest analysed radii are outside its application range, despite having proven to offer reasonable results. This third methodology aims to avoid the use of Eq. (9), directly relating the applied load $(P)$ in the numerical model with the obtained strain energy density. In fact, it is based on the existing proportionality relation between $P$ and the mean strain energy density corresponding to a given control area $(\bar{W})$. This proportionality is squared (Eqs. $(6,10,11))$, so that twice the applied load $(2 P)$ involves four times the average strain energy density $(4 \bar{W})$.

On this basis, Method $\mathrm{C}$ calculates, using finite element analyses, the necessary load for the mean strain energy density $(\bar{W})$ to be equal to the critical strain energy density $\left(W_{c}\right)$. This load defines the failure condition and will therefore be equal to the predicted failure load $\left(P_{S E D}\right)$.

The results of this last proposed methodology are depicted in Fig. 10. It is generally observed that the accuracy of the predictions is quite reasonable for the largest notch radii (e.g. Fig. 10d), where the use of [39] was theoretically out of application. However, the predicted failure loads for the smallest notch radii do not provide such good results and there is a clear and general tendency to overestimate them (e.g. Fig. 10b and Fig. 10f). Finally, the results corresponding to the granite (Fig. 10a) are noticeably above the theoretical failure line, which implies an overestimation factor of around 1.4 on average. Among all the studied rocks, the granite is the one with the largest critical radius and with the smallest specimen height (Fig. 4a). For this reason, the influence of the boundary is more noticeable than in the rest of rocks. Besides, Method C directly applies Eq. (6) for the fracture assessment, which is theoretically only valid when the control area embraces the semi-circular edge of the notch and not its rectilinear flanks [26]. This statement justifies the worsening of the results in Method C, especially in the case of the granite and in the case of evaluating the failure of the smallest notch radii. However, this effect is somehow smoothen when applying Method B, where the fracture is assessed according to Creager and Paris [39] through the application of Eq. (9).

Finally, it should be pointed out that although Method C avoids the use of Eq. (9), it requires the realization of a different numerical model for each test condition, that is, one for each material type and notch radius. This implies an important drawback, as the required workload for the fracture assessment increases considerably. 
a)

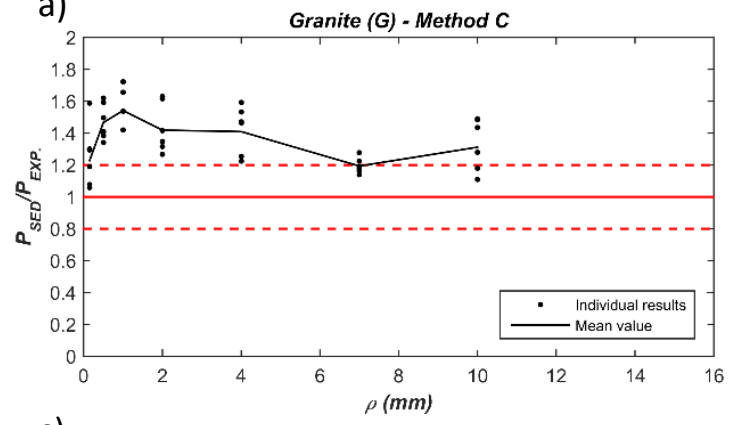

c)

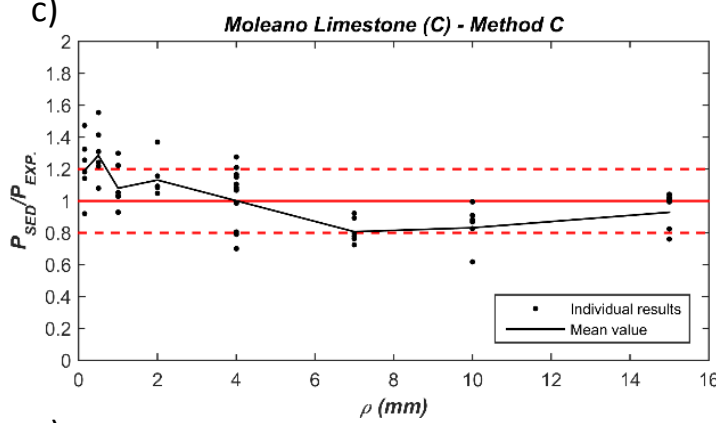

e)

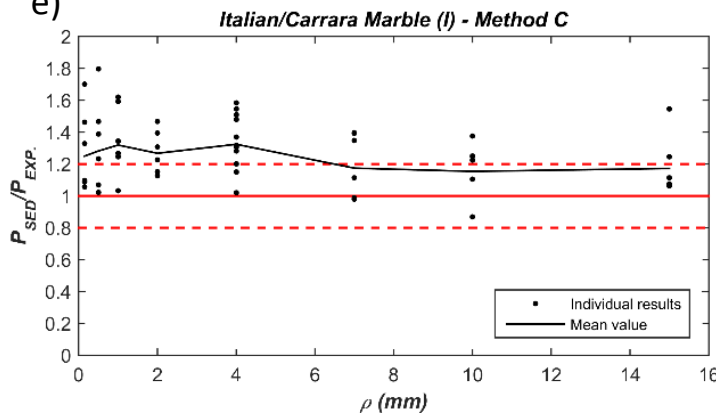

b)

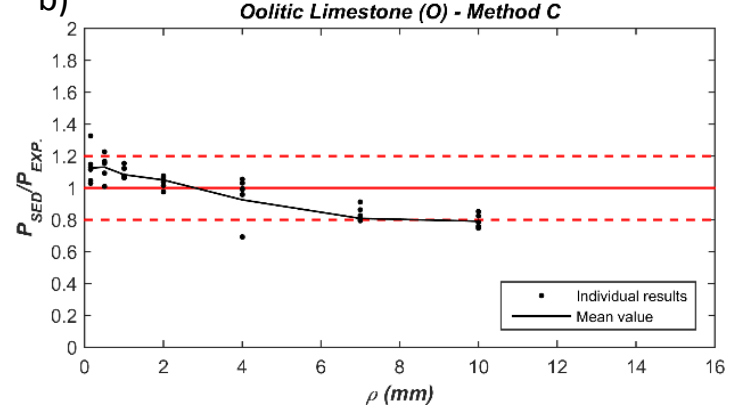

d)

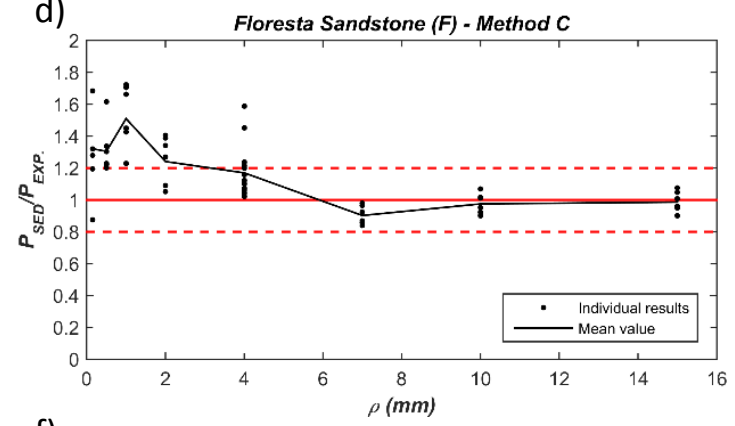

f)

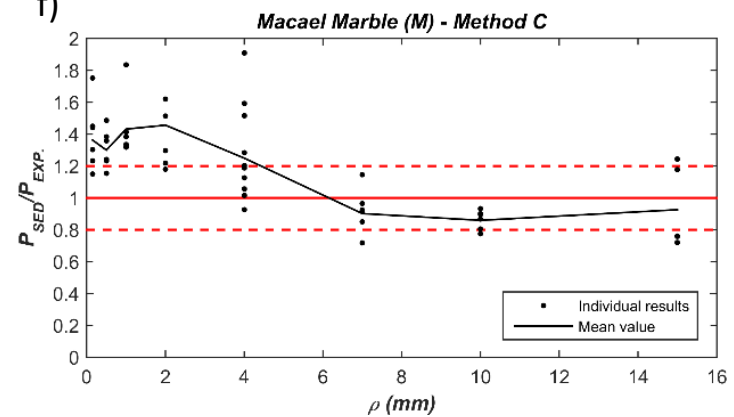

Figure 10. SED predictions (Method C) of the failure load for each rock.

\section{CONCLUSIONS}

This paper presents the fracture analysis of six different types of rocks, which is based on two main aspects: firstly, on the results of an exhaustive experimental program described in Section 4; secondly, on the application of the Strain Energy Density (SED) criterion for the prediction of fracture loads, which is applied through three different methods (here named A, B and C).

After observing and analysing the results obtained when using these three methods, several conclusions must be highlighted: The SED criterion has proven to provide reasonable fracture load predictions within a range of $\pm 20 \%$ with respect to the average experimental failure loads. In this sense, the results of the Carrara Marble offer the poorest fitting, probably because of the high scatter observed in the experimental tests.

Method A provides a good agreement between the predicted and the experimental failure loads, avoiding the use of numerical analyses and using tabulated values of the $H$ function (and, 
when necessary, their corresponding extrapolation). By contrast, Method B requires a simple numerical analysis in order to calculate the $H$ function. The best results correspond to the numerical model with the smallest notch radius $\left(\rho_{\text {fem }}=0.15 \mathrm{~mm}\right)$, and it has been demonstrated that the results of Method B (derived from the numerical model with $\rho_{\text {fem }}=1$ $\mathrm{mm}$ ) and Method A (whose tabulated values were also numerically obtained for $\rho_{\text {fem }}=1 \mathrm{~mm}$ ) are quite similar in the comparable range of values. Both Method A and B provide reasonable results even beyond the application range of the Creager and Paris stress distribution, which is supposed to be only valid for long and narrow notches. Conversely, Method $\mathrm{C}$ requires a more laborious numerical modelling analysis than Method B, but avoids the use of the Creager and Paris stress distribution. Satisfactory fracture load predictions are obtained for the largest notch radii with this third method, while for the smallest notches significant overestimations are generated.

Finally, it can be concluded that in the case of rocks the size of the control areas are relatively large. Thus, especial care must be taken in order to ensure that the influence of the boundary can really be neglected. One solution to this problem is applying the Method B with a sufficiently small $\rho_{\text {fem }}$ value that guarantees tiny critical radii. In this way, the local stress field evaluated from the notch tip to a radial distance $R_{c}$ will still be governed by the Generalised Notch Stress Intensity Factor $K_{I}$ and the assumed hypothesis will be valid.

\section{ACKNOWLEDGEMENTS}

The authors of this work would like to express their gratitude to the Spanish Ministry of Economy and Competitiveness and to the European Regional Development Fund (ERDF) for financing the National Plan Project (Ref.: BIA2015-67479-R) under the name of "The Critical Distance in Rock Fracture".

\section{REFERENCES}

[1] Whittaker B.N., Singh R.N., Sun G. Rock Fracture Mechanics: Principles, Design, and Applications. Elsevier, 1992.

[2] Aliabadi M.H. Fracture of Rock. WIT Press, 1999.

[3] Jaeger J.C., Cook N.G., Zimmerman R. Fundamentals of Rock Mechanics, 4th ed. WileyBlackwell, 2007.

[4] Niu L.S., Chehimi C., Pluvinage G., 1994. Stress field near a large blunted V notch and application of the concept of notch stress intensity factor to the fracture of very brittle materials. Eng Fract Mech, 1994, 49 325-335. 
[5] Pluvinage G. Fatigue and fracture emanating from notch; the use of the notch stress intensity factor. Nucl Eng Des, 1998, 185 173-184.

[6] Taylor D. The Theory of Critical Distances: A New Perspective in Fracture Mechanics. Elsevier, London, 2007.

[7] Gómez F.J., Elices M., Valiente A. Cracking in PMMA containing U-shaped notches. Fatigue Frac Eng Mat Struct, 2000, 23 795-803.

[8] Dugdale D.S. Yielding of steel sheets containing slits. J Mech Phys Solids, 1960, 8 100-108.

[9] Barenblatt G.I. The formation of equilibrium cracks during brittle fracture. General ideas and hypothesis. Axially symmetric cracks. J Appl Math Mech, 1959, 23 622-636.

[10] Gómez F.J., Elices M. Fracture of components with V-shaped notches. Eng Fract Mech, 2003a, 70 1913-1927.

[11] Gómez F.J., Elices M. A fracture criterion for sharp V-notched samples, Int J Fract, 2003b, $123163-175$.

[12] Gómez F.J., Elices M. A fracture criterion for blunted V-notched samples. Int J Fract, 2004, $127239-264$.

[13] Gómez F.J., Elices M., Planas J. The cohesive crack concept: application to PMMA at 60C. Eng Fract Mech, 2005, 72 1268-1285.

[14] Lazzarin P., Zambardi R. A finite-volume-energy based approach to predict the static and fatigue behaviour of components with sharp V-shaped notches. Int J Fract, 2001, 112 275-298. [15] Lazzarin P., Berto F. Some expressions for the strain energy in a finite volume surrounding the root of blunt V-notches. Int J Fract, 2005, 135 161-185.

[16] Cicero S., Berto F., Ibáñez Gutiérrez F.T., Procopio I., Madrazo V. SED criterion estimations of fracture loads in structural steels operating at lower shelf temperatures and containing $U$ notches. Theor Appl Fract Mech, 2017, 90 234-243.

[17] Neuber H. Theory of Notch Stresses. Springer-Verlag, Berlin, 1958.

[18] Erdogan F., Sih C.G. On the crack extension in plates under plane loading and transverse shear. J Basic Eng, 1963, 85 519-525.

[19] Berto F., Campagnolo A., Ayatollahi M.R. Brittle Fracture of Rounded V-Notches in Isostatic Graphite under Static Multiaxial Loading. Phys Mesomech, 2015, 18 283-297.

[20] Berto F., Ayatollahi M.R., Campagnolo A. Fracture tests under mixed mode I + III loading: an assessment based on the local energy. Int J Damage Mech, 2016, 26 881-894.

[21] Campagnolo A., Berto F., Leguillon D. Fracture assessment of sharp V-notched components under Mode II loading: a comparison among some recent criteria. Theor Appl Fract Mech, 2016, 85 217-226. 
[22] Torabi A.R., Berto F., Campagnolo A., Akbardoost J. Averaged strain energy density criterion to predict ductile failure of U-notched Al 6061-T6 plates under mixed mode loading. Theor Appl Fract Mech, 2017, 91 86-93.

[23] Campagnolo A., Meneghetti G., Berto F., Tanaka K. Crack initiation life in notched steel bars under torsional fatigue: Synthesis based on the averaged strain energy density approach. Int J Fatigue, 2017, 100 563-574.

[24] Berto F., Campagnolo A., Chebat F., Cincera M., Santini M. Fatigue strength of steel rollers with failure occurring at the weld root based on the local strain energy values: modelling and fatigue assessment. Int J Fatigue, 2016, 82 643-657.

[25] Berto F., Lazzarin P. A review of the volume-based strain energy density approach applied to V-notches and welded structures. Theor Appl Fract Mech, 2009, 523 183-194.

[26] Berto F., Lazzarin P. Recent developments in brittle and quasi-brittle failure assessment of engineering materials by means of local approaches. Mater Sci Eng R Rep, 2014, 75, 1-48.

[27] Aliha M.R.M., Berto F., Mousavi A., Razavi S.M.J. On the applicability of the ASED criterion for predicting mixed mode I+II fracture toughness results of a rock material. Theor Appl Fract Mech, 2017, 92 198-204.

[28] Berto F., Ayatollahi M.R., Borsato T., Ferro P. Local strain energy density to predict sizedependent brittle fracture of cracked specimens under mixed mode loading. Theor Appl Fract Mech, 2016, 86 217-224.

[29] Cicero S., García T., Castro J., Madrazo V., Andrés D. Analysis of notch effect on the fracture behaviour of granite and limestone: An approach from the Theory of Critical Distances. Eng Geol, 2014, 177 1-9.

[30] Justo J., Castro J., Cicero S., Sánchez-Carro M.A., Husillos R. Notch effect on the fracture of several rocks: Application of the Theory of the Critical Distances. Theor Appl Fract Mech, 2017, $90251-258$.

[31] Yosibash Z., Bussiba A.R., Gilad I. Failure criteria for brittle elastic materials. Int J Fract, 2004, 125 307-333.

[32] Filippi S., Lazzarin P., Tovo R., 2002. Developments of some explicit formulas useful to describe elastic stress fields ahead of notches in plates. Int J Solids Struct, 2002, 39 4543-4565. [33] UNE-EN 1926, 2007. Natural stone test methods - Determination of uniaxial compressive strength, AENOR, (Spanish).

[34] UNE-EN 14580, 2006. Natural stone test methods - Determination of static elastic modulus, AENOR, (Spanish).

[35] UNE 22950-2, 1990. Mechanical properties of rocks. Strength determination tests. Part 2: tensile strength. Indirect determination (Brazilian test), AENOR, (Spanish). 
[36] CEN/TS 14425-1 2003. Advanced Technical Ceramics - Test Methods for Determination of Fracture Toughness of Monolithic Ceramics - Part 1: Guide to Test Method Selection, Committee for Standarization, European.

[37] UNE-EN 13161, 2008. Natural Stone Test Methods - Determination of Flexural Strength under Constant Moment, AENOR (Spanish).

[38] Srawley J., Gross B. Cracks and fracture. ASTM Spec Tech Publ, 1976, 601 559-579.

[39] Creager M., Paris C. Elastic field equations for blunt cracks with reference to stress corrosion cracking. Int J Fract, 1967, 3 247-252.

[40] Tada H., Paris P.C., Irwin G.R. The Stress Analysis of Cracks Handbook. 2nd Ed., Paris Productions, St. Louis, MO, 1985.

[41] Brinkgreve R.B.J., Kumarswamy S., Swolfs W.M. Plaxis 2D 2015 Manual. Plaxis bv, the Netherlands, 2015. 